University of Nebraska - Lincoln

DigitalCommons@University of Nebraska - Lincoln

Entomology Papers from Other Sources

Entomology Collections, Miscellaneous

1998

Distribution of the Tarnished Plant Bug (Heteroptera: Miridae) Within Cotton Plants

Gordon Snodgrass

USDA-ARS

Follow this and additional works at: https://digitalcommons.unl.edu/entomologyother

Part of the Entomology Commons

Snodgrass, Gordon, "Distribution of the Tarnished Plant Bug (Heteroptera: Miridae) Within Cotton Plants" (1998). Entomology Papers from Other Sources. 55.

https://digitalcommons.unl.edu/entomologyother/55

This Article is brought to you for free and open access by the Entomology Collections, Miscellaneous at DigitalCommons@University of Nebraska - Lincoln. It has been accepted for inclusion in Entomology Papers from Other Sources by an authorized administrator of DigitalCommons@University of Nebraska - Lincoln. 


\title{
Distribution of the Tarnished Plant Bug (Heteroptera: Miridae) Within Cotton Plants
}

\author{
GORDON L. SNODGRASS
}

Southern Insect Management Research Unit, USDA-ARS, P.O. Box 346, Stoneville, MS 38776

\begin{abstract}
Environ. Entomol. 27(5): 1089-109.3 (1998)
ABSTRACT The within-plant distribution of the tarnished plant bug, Lygus lineolaris (Palisot de Beauvois), in cotton, Gossypium hirsutum L., was determined during June through the lst week in August in 1992 and 1993 at Stoneville, MS. Locations of adults and nymphs in cotton were determined weekly using visual searches of whole plants or plant sections (mainstem terminals, upper and lower plant halves below the mainstem terminals). The distributions of adults and nymphs found in the morning (0900-1100 hours) in 1992 were not significantly different from their distributions found in the afternoon (1300-1500 hours). Adults had a significantly different distribution than nymphs on vegetative structures (mainly leaves), fruiting structures (squares, bolls, and blooms) and mainstem terminals in both years. The distributions of adults and nymphs also were significantly different in both years on the mainstem terminals and upper and lower plant halves below the terminal. Nymphs and adults were found in both years to have $75 \%$ of their populations (on average) in the mainstem terminal plus the fruit and vegetative structures on the top 6 nodes of the plant. Nymphs showed a strong preference for fruiting structures, and high percentages of adults were found on vegetative structures through the first $3 \mathrm{wk}$ of squaring (June through the lst week in July) in both years. Adults then became more dispersed among the vegetative structures, fruit, and mainstem terminals. These types of distributions would make the drop cloth an excellent method for sampling nymphs, whereas the sweep net would work well for adults especially through the first $3 \mathrm{wk}$ of squaring. If visual examination of plants for nymphs and adults is used to sample cotton, it should include mainstem terminals plus vegetative and fruiting structures in the upper halves of plants.
\end{abstract}

KEY WORDS Lygus lineolaris, cotton, within-plant distribution

THE TARNISHED PLANT bug, Lygus lineolaris (Palisot de Beauvois), has a very wide host plant range and is a pest of many crops grown in North America (Young 1986). It can damage presquaring cotton, Gossypium hirsutum L., and cause various growth abnormalities along with a delay in fruiting and boll maturity (Hanney et al. 1977). Pack and Tugwell (1976) found that tarnished plant bugs preferred to feed on pinhead $(<3$ $\mathrm{mm}$ ) squares when given a choice of feeding on bolls, large squares, or pinhead squares. They also found that plant bug damage to bolls could cause yield loss, and feeding damage to older squares could cause them to shed later as bolls, or produce malformed bolls. Tarnished plant bug damage during fruiting also can cause delayed boll maturity and significant yield loss (Scott et al. 1986).

Control of tarnished plant bugs in cotton is mainly by use of insecticides, although this control method has become less effective in some areas because of the development of multiple insecticide resistance in some populations (Snodgrass and Elzen 1995, Snodgrass 1996). The decision to treat cotton with an insecticide for plant bug control can be made using recommended treatment thresholds. These thresholds are static nominal ones (Poston et al. 1983, Benedict et al. 1989) that have been determined by researchers and Cooperative Extension Service personnel using mainly field experience. Currently, there is a need to test treatment thresholds for plant bugs in replicated experiments in cotton to determine how well they are working. Treatment thresholds are based on numbers of plant bugs, and additional information on the accuracy of the different sampling methods used for plant bugs in cotton is needed. Detailed information on the distribution of tarnished plant bugs in cotton would help in the design of sampling experiments. Currently, the only study of the within-plant distribution of Lygus in cotton was by Wilson et al. (1984). They studied the western tarnished plant bug, L. hesperus Knight, and found that adults and nymphs during the growing season were on average located on the 5 th through 7 th nodes from the terminal. About twice as many adults were on bolls as on squares; the reverse was observed for nymphs.

The current study was conducted to determine the within-plant distribution of the tarnished plant bug in cotton to provide information needed for studies on sampling this pest in cotton.

\section{Materials and Methods}

The study was conducted in 1992 and 1993 in a 0.5-ha field of 'DES119' cotton located at Stoneville, MS. Cotton was planted on 5 May 1992 and 12 May

0046-225X/98/1089-1093802.00/0 @ 1998 Entomological Society of America 
1993, and no insecticides were used in the field for control of cotton pests during either year of the study. A natural infestation of tarnished plant bugs occurred in the field in both years. Plant height and number of mainstem nodes (node 1 was the lst node below the apical bud of the mainstem with a fully expanded leaf) were recorded from 50 randomly selected plants in each test week. Counts of squares, flowers, and bolls also were taken from the 50 plants each test week when fruiting began. On all test dates, locations of tarnished plant bugs in the cotton were determined by visual examination, and the plant structure and mainstem node location of each adult and nymph found were recorded. Visual searches were taken using observers ( 3 in 1992, 4 in 1993) who examined plants for plant bugs as they moved down rows while spaced at least 2 rows apart. Plants to be examined were selected at random using a fiberglass rod $(0.95 \mathrm{~cm}$ diameter, $1.8 \mathrm{~m}$ long). Each observer placed a rod down the row on the ground ahead of him parallel to the row. He then examined the plant nearest to the far end of the rod. After examining a plant, the rod was again extended down the row and the process repeated. Whole-plant examinations were made on the first 2 sample weeks of 1992 ( 50 per observer), and first 3 sample weeks of 1993 (100 per observer). In the remaining sample weeks of both years, the plants were too large to make whole-plant examinations without disturbing the plant bugs before they could be observed. Therefore, plants were then searched by examining sections into which each plant was divided. The plant sections used for examination were the mainstem terminal, and upper and lower plant halves obtained by visually dividing the plant below the mainstem terminal. The entire terminal was searched, whereas an upper or lower plant half was visually searched from the mainstem to the observer. The plant half opposite the observer was not searched, because the observer could not see any plant bug he might have disturbed on that row side as he searched the plant on the row side near him. On each test date where plants were examined by sections, each observer took 50 samples (except in the 4 th test week of 1993 when 100 samples were taken by each observer). Each sample included a search of a terminal, a search of an upper plant half, and a search of a lower plant half taken from 3 separate plants. The 3 plants in each sample were selected at random using the fiberglass rod, and after each sample the observer moved to the opposite side of the row before taking the next sample. This was done to negate any effect that light (the rows ran east and west) might have on the distribution of the bugs. The entire test in 1992 was performed twice on each test date, once in the morning between 0900 and 1100 hours, and in the afternoon between 1300 and 1500 hours. The test was performed in 1993 only during the morning hours.

To compare the distributions of adults and nymphs on the plants, a chi-square test was used. One distribution compared was numbers of adults and nymphs found on the mainstem terminals, upper plant halves, and lower plant halves. A 2nd comparison was num- bers of adults and nymphs found in the terminal, on vegetative structures (mainly leaves, also stems and petioles), or on fruiting structures (squares, flowers, and bolls). Each comparison was made by constructing contingency tables and using the maximum likelihood chi-square procedure (PROC FREQ, SAS Institute 1989). In 1992, the distributions of adults and nymphs found in cotton in the morning were compared with their distributions in the afternoon. In an additional analysis of the data from each year, the cumulative number of adults or nymphs in the terminal and in the mainstem nodes below it were calculated for each test date. Samples where no plant bugs were found were ignored. Cumulative numbers were converted to percentages of the total number of adults or nymphs found on each date by node down the plants. The nodes at which $75 \%$ of the adults or nymphs were accumulated were found by interpolation from a node by a cumulative percentage table. Using date as a replication, analysis of variance (ANOVA) was performed (PROC GLM, SAS Institute 1989) for a randomized complete block design with 8 replications in 1992 (the 1st sample week in 1992 was not used because no nymphs were found) and 7 in 1993, and 2 treatments (adults and nymphs).

\section{Results}

Plants on which tarnished plant bugs were found totaled 841 in 1992 and 805 in 1993. During the $2 \mathrm{yr}$, 8,400 plants were partially searched by sections and 2,100 were completely searched by whole-plant examination. Most observations were for a single adult or nymph on each plant; however, multiple numbers were found on $261(15.9 \%)$ of the plants. The largest numbers of nymphs and adults found on a single plant were 5 and 6 , respectively. Squares had the highest number of adults (3) or nymphs (3) found in a single observation.

Numbers of adults and nymphs in 1992 (expressed as a percentage of the total number of each found) in the mainstem terminals, and in upper and lower plant halves in the morning, were not significantly different from their percentages found in these locations in the afternoon (adults $\chi^{2}=0.29$, df $=2, P>0.865$; nymphs $\left.\chi^{2}=4.1, \mathrm{df}=2, P>0.126\right)$. Percentages of adults and nymphs found in the morning on vegetative plant parts, fruiting structures, and mainstem terminals also were not significantly different from their percentages found on these plant structures in the afternoon (adults $\chi^{2}=0.865$, $\mathrm{df}=2, P>0.649$; nymphs $\chi^{2}=$ 4.137, $\mathrm{df}=2, P>0.126)$. Therefore, the statistical analyses were repeated using combined data from the morning and afternoon tests in 1992.

The distributions of adults and nymphs (using combined morning and afternoon data in 1992) on mainstem terminals and upper and lower plant halves were significantly different in $1992\left(\chi^{2}=7.39\right.$, df $=2, P<$ $0.025)$ and in $1993\left(\chi^{2}=11.19\right.$, df $\left.=2, P<0.004\right)$ (Table 1). In both years, higher percentages of nymphs than adults were found in the lower plant halves-28\% versus $21 \%$ in $1992 ; 33 \%$ versus $22 \%$ in 
Table 1. Distribution of tarnished plant bug adults and nymphs on cotton plants by search location

\begin{tabular}{|c|c|c|c|c|c|c|c|c|}
\hline \multirow{3}{*}{ Stage } & \multicolumn{6}{|c|}{ No. found by search location } & \multirow{3}{*}{ Total } & \multirow{3}{*}{$x^{2}$} \\
\hline & \multicolumn{2}{|c|}{$\begin{array}{c}\text { Mainstem } \\
\text { terminal }\end{array}$} & \multicolumn{2}{|c|}{$\begin{array}{c}\text { Upper } \\
\text { plant } \\
\text { half } \\
\end{array}$} & \multicolumn{2}{|c|}{$\begin{array}{c}\text { Lower } \\
\text { plant } \\
\text { half }\end{array}$} & & \\
\hline & No. & $\%^{a}$ & No. & $\%$ & No. & $\%$ & & \\
\hline \multicolumn{9}{|c|}{1992} \\
\hline Adults & 52 & 23 & 127 & 56 & 48 & 21 & 227 & $7.4^{b}$ \\
\hline Nymphs & 85 & 15 & 308 & 57 & 151 & 28 & 544 & \\
\hline \multicolumn{9}{|c|}{1993} \\
\hline Adults & 34 & 12 & 181 & 66 & 59 & 22 & 274 & $11.2^{b}$ \\
\hline Nymphs & 42 & 12 & 189 & 55 & 115 & 33 & 346 & \\
\hline
\end{tabular}

${ }^{a}$ Percentage of the total of adults or nymphs found 2 July through 6 August 1992, and 14 July through 4 August 1993

${ }^{b}$ Chi-squared comparisons between adults and nymphs in their distribution on mainstem terminals, upper plant halves, and lower plant halves are significant for $1992(P<0.025)$ and $1993(P<0.004)$.

1993. In the upper plant halves, the percentages of adults (56\%) and nymphs (57\%) found in 1992 were about the same; but in 1993, more adults $(66 \%)$ than nymphs $(55 \%)$ were found in the upper plant halves. Adults (12\%) and nymphs (12\%) were equal in 1993 in the mainstem terminals, whereas in 1992 more adults $(23 \%)$ than nymphs (15\%) were found. Calculation of cumulative percentages of adults and nymphs (found in the mainstem terminal and at mainstem nodes down the plant) showed that in 1992 the average node below the mainstem terminal at which $75 \%$ of the population accumulated was 5.6 for adults and 5.0 for nymphs; in 1993 it was 4.7 for adults and 5.8 for nymphs. The mean number of nodes needed to accumulate $75 \%$ of the adults was not significantly different from the mean number of nodes required to accumulate $75 \%$ of the nymphs in either year $(F=$ $1.91 ; \mathrm{df}=1,7 ; P=0.21$ in $1992 ; F=4.50 ; \mathrm{df}=1,6 ; P=$ 0.08 in 1993).

The distributions of adults and nymphs on vegetative plant structures, fruiting structures, and in the mainstem terminals (using combined morning and afternoon data in 1992) were significantly different in $1992\left(\chi^{2}=166.40, \mathrm{df}=2, P<0.001\right)$ (Table 2$)$ and in $1993\left(\chi^{2}=79.87, \mathrm{df}=2, P<0.001\right)$ (Table 3$)$. The differences in both years were caused by higher percentages of nymphs compared with adults on fruiting structures-69\% versus $38 \%$ in $1992 ; 80 \%$ versus $54 \%$ in 1993. Adults had higher percentages on vegetative structures in both years compared with nymphs-39\% versus $10 \%$ in $1992 ; 33 \%$ versus $11 \%$ in 1993. Similar percentages of adults and nymphs were found in the mainstem terminals in both years-23\% versus $21 \%$ (nymphs) in 1992; 13\% versus 9\% (nymphs) in 1993.

Nymphs on fruiting structures increased to their highest percentages of the total number found on 16 July 1992 (88\%) (Table 2) and 20 July 1993 (90\%) (Table 3). Squares, bolls, and blooms were all present in the field beginning on 16 July 1992 and 14 July 1993, and from these weeks through the remainder of the study in both years, 288 nymphs were found in 1992 and 277 in 1993. In $1992,194(67 \%), 59(21 \%)$, and 35 (12\%) of the 288 nymphs were found on squares, blooms, and bolls, respectively. In 1993, 224 (81\%), 36 (13\%), and 18 (6\%) of the 277 nymphs were found on squares, blooms, and bolls, respectively. The percentages of nymphs on vegetative structures were highest (32\%) on 23 June 1992 and on this date again in 1993 (20\%). It then declined and remained $<10 \%$ for most of the study in 1992 , and at $\leq 20 \%$ in 1993 . On mainstem terminals, the initial percentage of nymphs found in 1992 was high $(63 \%)$, then declined to $3 \%$ on 16 July and remained low during the rest of the study. The nymphal population in the mainstem terminal was $\geq 15 \%$ of the total number of nymphs found in each week of 1993.

Adults initially had a high percentage of their total number on vegetative structures during the first $3 \mathrm{wk}$ of squaring (June through the 1st wk of July) in 1992 $(64-74 \%)$ and $1993(47-56 \%)$ (Tables 2 and 3). These percentages declined by mid-July in both years as numbers of adults increased on fruiting structures. By late July, adults had again increased on vegetative

Table 2. Distribution of tarnished plant bug adults and nymphs on cotton plants in 1992

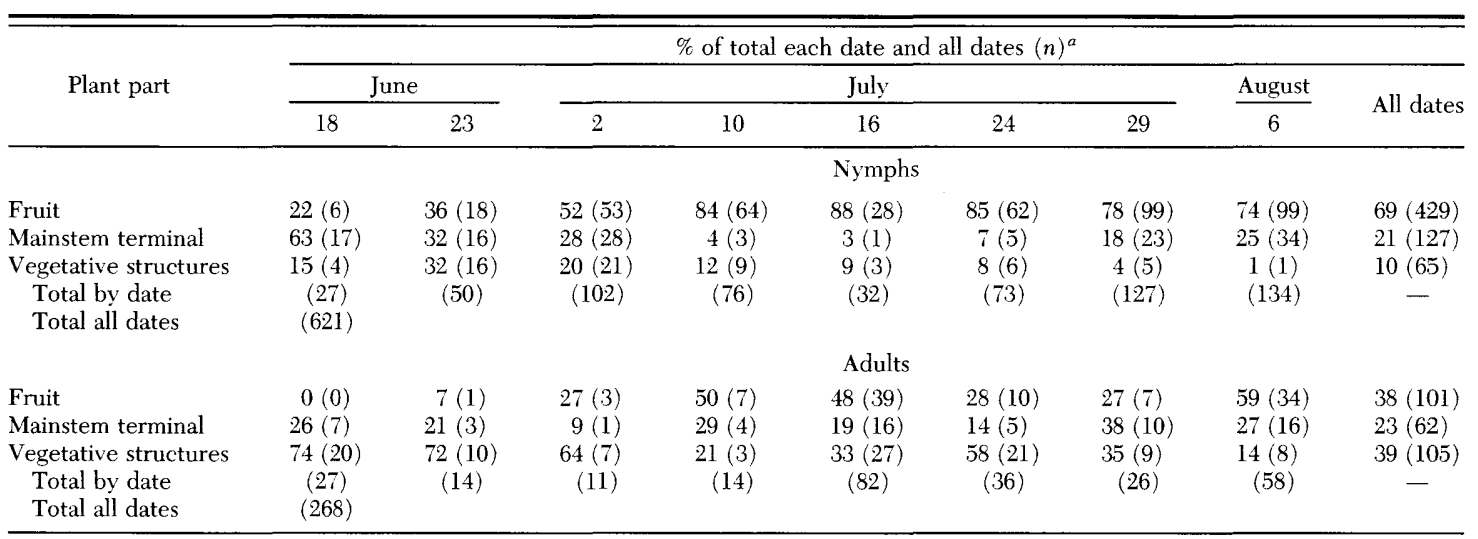

Distributions of adults and nymphs on vegetative structures, fruit, and mainstem terminals were significantly different $\left(\chi^{2}=166.4, P<0.001\right)$

${ }^{a} n$, number of adults or nymphs found on the plant part on each date. 
Table 3. Distribution of tarnished plant bug adults and nymphs on cotton plants in 1993

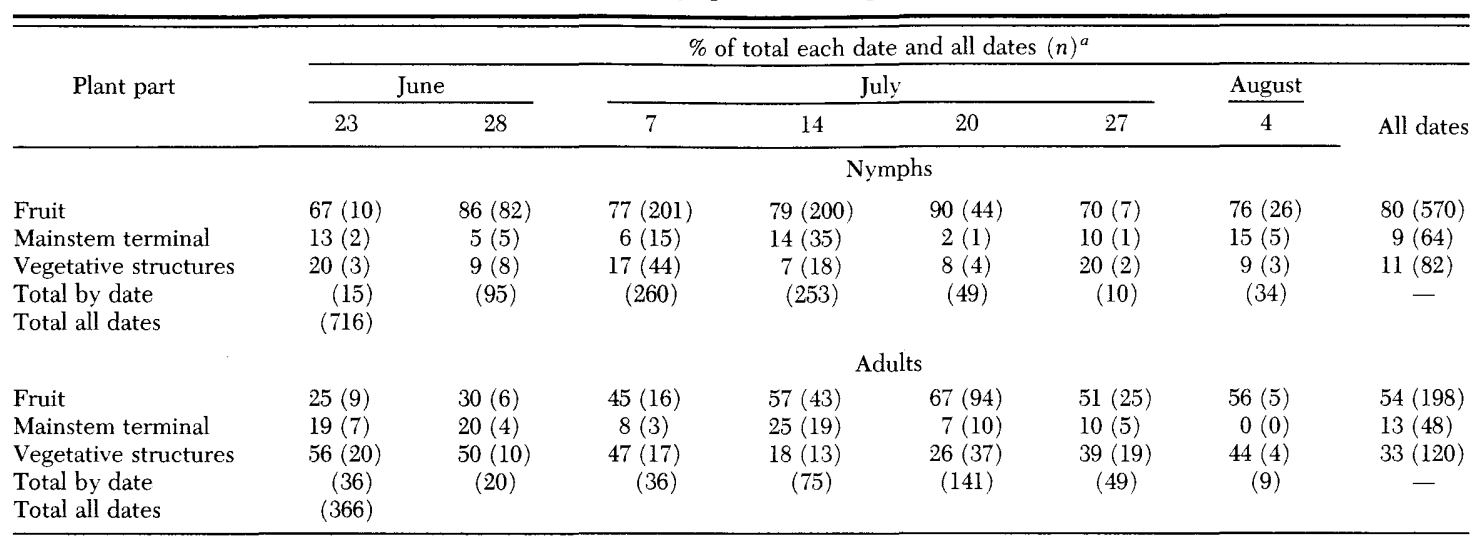

Distributions of adults and nymphs on vegetative structures, fruit, and mainstem terminals were significantly different $\left(\chi^{2}=79.9, P<0.001\right)$. ${ }^{a} n$, number of adults or nymphs found on the plant part on each date.

structures in both years. This increase in 1992 was followed by another decrease in the percentage of adults on vegetative structures with an accompaning increase in percentages on fruit and on mainstem terminals. The increase on vegetative structures in 1993 was accompanied mainly by a decrease in the percentage in the mainstem terminals. The percentage of adults found on fruit never exceeded $60 \%$ in any week in 1992 and only in 1 wk in 1993 (20 July). Ninety adults were found on fruiting forms in 1992 during the time period when squares, blooms, and bolls were all present in the field (16 July-6 August). Of these adults, 12 (13\%), 29 (32\%), and $49(55 \%)$ were on bolls, blooms, and squares, respectively. In 1993 a total of 167 adults were found (14 July-4 August), and 7 (4\%), 15 $(9 \%)$, and $145(87 \%)$ adults were found on bolls, blooms, and squares, respectively.

\section{Discussion}

In both years, $75 \%$ of the adults and nymphs were found an average of $\leq 6$ nodes below the mainstem terminal. These results are similar to those of Wilson et al. (1984), who reported L. hesperus nymphs and adults were found on average in the 5 th through 7 th nodes from the mainstem terminals. They also found that nymphs of $L$. hesperus had a preference for cotton squares compared with bolls. In the current study, 67 and $81 \%$ of the nymphs found on fruiting structures were found on squares in 1992 and 1993, respectively, during the time that squares, bolls, and blooms were present in the field. However, these data probably do not show nymphs having a preference for squares. The study was terminated in both years in the 1st week of August, and much larger numbers of squares than bolls or blooms were present each week in the field. Tarnished plant bug nymphs did show a preference for fruiting structures in cotton in 1992 and 1993, because in most weeks the percentages of nymphs on vegetative structures and mainstem terminals were $20 \%$ or less of the total number found.
Only 13 and $4 \%$ of adult plant bugs in 1992 and 1993, respectively, were found on bolls during the time that bolls, blooms, and squares were all present in the field. These results differ from those of Wilson et al. (1984) who found twice as many adult $L$. hesperus on bolls as were found on squares. However, the current study was terminated in the 1st week of August in both years, while the study by Wilson et al. (1984) was conducted throughout the growing season. Thus, they sampled fields late in the season when bolls were more prevalent.

During both years, adults dispersed over the different plant parts, whereas nymphs remained mostly on fruiting structures. The greater dispersal of the adults on the plants probably was caused by the greater mobility of the adults. In addition, adult feeding, mating, and oviposition behaviors probably contributed to their dispersal. For example, adult females are known to oviposit in several plant parts including squares, petioles, leaf scars, mainstem terminals, and in the pulvinuses of leaves (Bariola 1969, Benedict et al. 1983, Fleischer and Gaylor 1988).

The tendency for adults to have at least $50 \%$ of their population on vegetative structures (mainly leaves) and in the mainstem terminals would make the sweep net an efficient sampling tool. The sweep net would have been especially effective during the first 3-4 wk of the current study when a high percentage (47-74\%) of the adult population in both years was found mainly on leaves of relatively small plants. Wilson and Gutierrez (1980) thought that the sweep net sampled adult plant bugs better than nymphs because adults were found higher on the plants. The sweep net also was found to be better at capturing adults than nymphs by Young and Tugwell (1975) and Byerly et al. (1978).

As shown in the current study, visual examination of only mainstem terminals (a sampling method commonly used by growers and crop consultants) would not sample areas of the plant where a high percentage of the plant bug adults and nymphs were located. Rather, visual examinations should include the main- 
stem terminal along with fruit and vegetative structures found in the upper half of each plant. Young and Tugwell (1975) found that visual inspection of mainstem terminals was the least efficient method among several sampling methods they tested. However, Fleischer et al. (1985) found that carefully executed visual searches of the whole plant gave the most accurate estimates of plant bug nymphal populations in cotton.

The sweep net is known to do a poor job in sampling nymphs (Young and Tugwell 1975, Byerly et al. 1978 , Ellington et al. 1984, Fleischer et al. 1985, Snodgrass 1993). Byerly et al. (1978) thought that the sweep net would be relatively efficient when plants were small and the canopy was open. However, as the canopy closed, the sweep net would tend to sample only the upper parts of plants and become less efficient. The preference of nymphs for fruit, and the higher percentage of nymphs (compared with adults) in the lower halves of plants, make it difficult to sample nymphs with a sweep net. The drop cloth should be more efficient in sampling nymphs than the sweep net because it samples a larger area of each plant, and shaking or beating plants would more likely dislodge nymphs from fruit than sweeping. Studies by Young and Tugwell (1975), Fleischer et al. (1985), and Snodgrass (1993) all found the drop cloth to be better than the sweep net for capturing nymphs.

In summary, nymphs of the tarnished plant bug in cotton showed a strong preference for fruit during the growing seasons of $2 \mathrm{yr}$, whereas a high percentage of adults were found on vegetative structures (mainly leaves) through the first $3 \mathrm{wk}$ of square production (June through the 1st wk of July in both years). Adults then became more dispersed among the leaves, fruiting structures, and mainstem terminals during the remainder of both years. These types of distributions would make the drop cloth an excellent method for sampling nymphs, whereas the sweep net would work well for adults especially through the 3rd wk of squaring. If visual examination of plants for nymphs and adults is used, it should include mainstem terminals plus vegetative structures and fruiting structures in the upper half of each plant; a search of 6 nodes below the mainstem terminal would cover plant parts where an average $75 \%$ of the adults and nymphs were located.

\section{References Cited}

Bariola, L. A. 1969. The biology of the tarnished plant bug, Lygus lineolaris (Beauvois), and its nature and control on cotton. Ph.D. dissertation, Texas A\&M University, College Station.

Benedict, J. H., T. F. Leigh, and A. H. Hyer. 1983. Lygus hesperus (Heteroptera: Miridae) oviposition behavior, growth, and survival in relation to cotton trichome density. Environ. Entomol. 12: 331-335.

Benedict, F. L., K. M. El-Zik, L. R. Oliver, P. A. Roberts, and L. T. Wilson. 1989. Economic injury levels and thresholds for pests of cotton, pp. 144-145. In N. E. Frisbie, K. M. El-Zik, and L. T. Wilson [eds.], Integrated pest management systems and cotton production. Wiley, New York.

Byerly, K. F., A. P. Gutierrez, R. E. Jones, and R. F. Luck. 1978. A comparison of sampling methods for some arthropod populations in cotton. Hilgardia 46: 257-282.

Ellington, J., K. Kiser, G. Ferguson, and M. Cardenas. 1984. A comparison of sweep net, absolute, and Insectavac sampling methods in cotton ecosystems. J. Econ. Entomol. 77: 599-605.

Fleischer, S. J., and M. J. Gaylor. 1988. Lygus linolaris (Heteroptera: Miridae) population dynamics: nymphal development, life tables, Leslie matrices on selected weeds and cotton. Environ. Entomol. 17: 246-253.

Fleischer, S. J., M. J. Gaylor, and J. V. Edelson. 1985. Estimating absolute density from relative sampling of Lygus lineolaris (Heteroptera: Miridae) and selected predators in early to mid-season cotton. Environ. Entomol. 14: 709717.

Hanny, B. W., T. C. Cleveland, and W. R. Meredith, Jr. 1977. Effects of tarnished plant bug, (Lygus lineolaris), infestation on presquaring cotton, (Gossypium hirsutum). Environ. Entomol. 6: 460-462.

Pack, T. M., and P. Tugwell. 1976. Clouded and tarnished plant bugs on cotton: a comparison of injury symptoms and damage on fruit parts. Ark. Agric. Exp. Stn. Rep. Ser. 226

Poston, F. L., L. P. Pedigo, and S. M. Welch. 1983. Economic injury levels: reality and practicality. Bull. Entomol. Soc. Am. 29: 49-53.

Scott, W. P., J. W. Smith, and G. L. Snodgrass. 1986. Impact of early-season use of selected insecticides on cotton arthropod populations and yield. J. Econ. Entomol. 79: 797-804.

SAS Institute. 1989. SAS/STAT user's guide, version 6, 4th ed., vols. 1 and 2. SAS Institute, Cary, NC.

Snodgrass, G. L. 1993. Estimating absolute density of nymphs of Lygus lineolaris (Heteroptera: Miridae) in cotton using drop cloth and sweep-net sampling methods. J. Econ. Entomol. 86: 1116-1123.

1996. Insecticide resistance in field populations of the tarnished plant bug (Heteroptera: Miridae) in cotton in the Mississippi Delta. J. Econ. Entomol. 89: 783-790.

Snodgrass, G. L., and G. W. Elzen. 1995. Insecticide resistance in a tarnished plant bug population in cotton in the Mississippi Delta. Southwest. Entomol. 20: 317-323.

Wilson, L. T., and A. P. Guitierrez. 1980. Within-plant distribution of predators on cotton: comments on sampling and predator efficiencies. Hilgardia 48: 1-11.

Wilson, L. T., T. F. Leigh, D. Gonzalez, and C. Foristiere. 1984. Distribution of Lygus hesperus (Knight) (Miridae: Hemiptera) on cotton. J. Econ. Entomol. 77: 1313-1319.

Young, O. P. 1986. Host plants of the tarnished plant bug, Lygus lineolaris (Heteroptera: Miridae). Ann. Entomol. Soc. Am. 79: 747-762.

Young, S. C., and P. Tugwell. 1975. Different methods of sampling for clouded and tarnished plant bugs in Arkansas cotton fields. Ark. Agric. Exp. Stn. Rep. Ser. 219.

Received for publication 11 April 1997; accepted 27 May 1998. 